

\section{Sumário}

Ordenamiento ambiental del terRitorio y participación CiUdadana en Argentina: aportes posibles DESDE EL DERECHO 2

María Valeria Berros

Matéria ambiental nos tribunais da Austrália e nova Zelândia ................................................... 17 Marcio Oliveira Portella

Conservação da BIODIVERSIDADE E POLÍtICAS PÚbLICAS PARA AS ÁREAS PROTEGIDAS NO BRASIL: DESAFIOS E

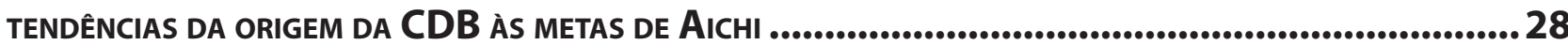

Ana Paula Leite Prates e Marta de Azevedo Irving

Dimensões linguísticas dA DESIGUALDADE No BrASIL: OS DIVERSOS NOMES LEGAIS DE UM MESMO FENÔMENo

Jefferson Carús Guedes

ECONOMIA, ÉTICA E TRIBUTAÇÃO: DOS FUNDAMENTOS DA DESIGUALDADE

Rafael Köche e Marciano Buffon

A REPARTIÇÃO de RENDAS ENTRE OS ENTES DA FEDERAÇÃO E SUA REPERCUSSÃo NA CARACTERIZAÇÃo DO FEDERALISMO BRASILEIRO: UMA INVESTIGAÇÃO ACERCA DO DESENVOLVIMENTO DO FEDERALISMO FISCAL-FINANCEIRO NO BRASIL.

Raquel Mousinho de Moura Fé

UMA AVALIAÇÃO DO ÍNDICE DE INCLUSÃO FINANCEIRA NOS ESTADOS DO NORDESTE BRASILEIRO

Diego Araujo Reis e Osvaldo Sousa Ventura

Fatores determinantes do Índice de Desenvolvimento Humano dos Municípios do Estado de São

PaUlo

Leandro Campi Prearo, Maria Clara Maraccini e Maria do Carmo Romeiro

As políticas públicas de acesso e difusão da cultura no Brasil e o caso do Programa Nacional de Apoio à Cultura. 157

Telma Rocha Lisowski

MoldANDO A "RESERVA do POSSível" NO TEMPO: A SUSTENTABILIDADE FISCAL COMO DIREITO DIFUSO FUNDAMENTAL. 171

Leonardo Romero Marino 
O PODER JUDICIÁRIO E A EFETIVAÇÃO DO DIREITO À SAÚDE

João Luis Nogueira Matias e Águeda Muniz

EDUCAÇÃo SUPERIOR NO BRASIL: OFERTA NA OMC, UMA REFLEXÃO DESMISTIFICADA, COM BASE EM DADOS ESTATÍSTICOS 208

Marcel Vitor Guerra

A GARANTIA DO DIREITO À EDUCAÇÃO DE CRIANÇAS E ADOLESCENTES NO CONTEXTO DAS POLÍTICAS PÚBLICAS BRASILEIRAS

André Viana Custódio e Rafael Bueno da Rosa Moreira

A POLÍCIA JUDICIÁRIA E O COMBATE À CRIMINALIDADE

Júlio Lopes Hott

Processo eleitoral e políticas Públicas: influÊnCias ReCíProcas.

Pablo Malheiros da Cunha Frota

SOCIEDADES PRIMITIVAS E DIREITO CONTEMPORÂNEO: DE QUE FORMA A JUSTIÇA TRIBAL PODE NOS AJUDAR A REPENSAR A NOSSA JUSTIÇA 303

Amanda Rodrigues e Tiago Themudo

DIREITO PRIVADO, JUSTIÇA DISTRIBUTIVA E O ARGUMENTO DA DUPLA DISTORÇÃO: UMA REVISÃO DA LITERATURA ...........318 Leandro Martins Zanitelli

DistorçõES NO CONTROLE CADASTRAL DAS ENTIDADES SINDICAIS E CONTRIBUIÇÃO SINDICAL Ricardo Bravo

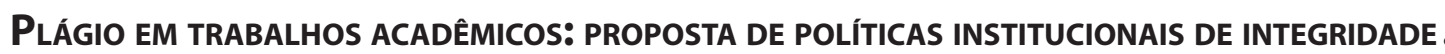
354 Maria Edelvacy Pinto Marinho e Marcelo Dias Varella 


\title{
Direito privado, justiça distributiva e o argumento da dupla distorção: uma revisão da literatura*
}

\author{
Private law, distributive justice, and the \\ double-distortion argument: a review of the \\ literature
}

Leandro Martins Zanitelli*

\begin{abstract}
Resumo
O presente trabalho apresenta "argumento da dupla distorção" (ADD), de Kaplow e Shavell, e uma síntese das críticas que lhe são endereçadas. Segundo o referido argumento, regras legais em geral, incluindo-se as do direito privado, devem atender à eficiência, deixando-se objetivos redistributivos para serem perseguidos (à medida que a perseguição desses objetivos contrarie a eficiência) exclusivamente pela tributação da renda. Com base em um inventário das críticas ao ADD encontradas na literatura, o trabalho também enumera linhas de investigação sobre as possibilidades de um uso redistributivo do direito privado.
\end{abstract}

Palavras-chave: Direito privado. Igualdade. Redistribuição. Dupla distorção.

\section{Abstract}

The paper presents Kaplow and Shavell's "double distortion argument" (DDA), as well as summarizes criticisms raised against it. According to the argument at issue, legal rules in general, including private legal rules, should aim at efficiency, leaving redistributive goals to be pursued (to the extent that pursuing those goals contradicts efficiency) exclusively through the income tax. Based on the objections against the DDA found in the existing literature, the paper describes lines of research concerning the possibilities of a redistributive private law.

Keywords: Private law. Equality. Redistribution. Double distortion.

* Recebido em 19/03/2015 Aprovado em 20/04/2015

** Doutor em Direito pela Universidade Federal do Rio Grande do Sul (UFRGS); Professor Adjunto de Direito Civil na Universidade Federal de Minas Gerais (UFMG). E-mail: leandrozanitelli@gmail.com

\section{INTRODUÇÃO}

A qual objetivo último, se algum, deve o direito privado, em seu todo, atender? Um ramo poderoso da literatura sobre política do direito privado, a análise econômica do direito, considera que esse objetivo constitui a eficiência. O mal do objetivo da eficiência, contudo, em qualquer das suas variantes, é a indiferença aos lotes individuais. Um estado de coisas ótimo, 
no sentido da eficiência, é um no qual alguns podem ter muito mais do que outros, ainda que não haja razão alguma (afora a própria eficiência) a justificar tal diferença. ${ }^{1}$

As implicações contraigualitárias da eficiência podem se tornar mais palatáveis, no entanto, se levarmos em consideração que ao direito privado corresponde apenas uma parte das políticas públicas, de modo que eventuais consequências indesejáveis de um direito privado eficiente possam ser, se não de todo desfeitas, ao menos minoradas pela aplicação das regras de algum outro setor. Mais propensos a aceitar a eficiência como objetivo para o direito privado, poderemos ficar ainda, caso haja uma razão qualquer, não apenas para contar com meios de redistribuição alternativos, como a tributação, como também para considerar que algum desses meios realiza a tarefa em questão com vantagem, isto é, mostra-se, como meio de redistribuição, superior ao direito privado. Se, finalmente, a razão para considerar outro meio de redistribuição superior ao direito privado for a própria eficiência, tanto mais inclinados ficaremos a ignorar a abandonar a pretensão de um direito privado igualitário quanto mais afinidade houver entre a nossa concepção de igualdade e a eficiência. A concepção de justiça igualitária de Rawls, para ficar com o exemplo mais proeminente dos últimos cinquenta anos, aproxima-se da eficiência ao exigir que as expectativas dos cidadãos em pior situação sejam maximizadas, ${ }^{2}$ o que impede um governo de abolir diferenças além do ponto em que essas diferenças se tornem vantajosas ao que estão em pior situação. Todo o restante sendo igual, um rawlsiano é, pois, compelido a escolher como meio legal de redistribuição aquele que maximiza as expectativas dos cidadãos mencionados, e é provável que esse meio seja o que menos desperdiça recursos ou, em outras palavras, o mais eficiente.

Há vários argumentos contra o uso redistributivo do direito privado. ${ }^{3}$ Um é o argumento da imprecisão, segundo o qual as regras de direito privado são meios inadequados de redistribuição porque se aplicam a classes de pessoas diferentes das que verdadeiramente importam, quando o que se tem em vista é a justiça distributiva. Se, por hipótese, nossos padrões de justiça requererem que os pobres sejam beneficiados com mais recursos, uma lei de locações com regras favoráveis aos inquilinos seria um meio impreciso para alcançar esse fim, porque nem todos os inquilinos são pobres. ${ }^{4}$ Outro argumento, o do "escape contratual" (contracting around), chama a atenção para o fato de que a pretensão redistributiva de certas regras de direito privado esbarra na liberdade para estipulação das cláusulas contratuais. Além de imprecisa, uma regra de locações que obrigasse a indenizar o inquilino pela realização de benfeitorias, ambicionando, assim, transferir recursos de locadores para locatários, poderia ter o seu propósito frustrado por uma simples elevação dos aluguéis que compensasse os locadores pela despesa com o pagamento das indenizações.

Nenhum argumento contra regras redistributivas de direito privado tem ocupado mais a atenção da literatura nos últimos tempos, entretanto, do que o argumento da "dupla distorção" (ADD), de Kaplow e Shavell. ${ }^{5} \mathrm{O}$ ADD leva à conclusão de que o direito privado constitui não apenas um instrumento de redis-

1 À luz da eficiência, um estado de coisas pode ser considerado ótimo em dois sentidos, os quais constituem, pois, duas acepções diversas de eficiência. No sentido de Pareto, atinge-se ponto ótimo quando não é possível melhorar a situação de alguém sem também com isso piorar ao menos a de outra pessoa. No sentido de Kaldor-Hicks, um ponto ótimo é aquele no qual não se pode melhorar a situação de alguém sem que a soma das perdas infligidas a outras pessoas seja superior aos ganhos somados. Para ilustrar a afirmação do texto, imaginemos um estado de coisas atual em que as duas únicas pessoas, $\mathrm{A}$ e $\mathrm{B}$, tenham, respectivamente, $2 \mathrm{e}$ 8, e que a única mudança possível seja para um estado de coisas em que A passará a ter 4 e B, 5. Em tal hipótese, o estado inicial é reputado ótimo em qualquer dos dois sentidos recém referidos, não havendo qualquer razão de eficiência para uma alteração do status quo. O estado inicial é ótimo no sentido de Pareto porque a melhora da situação de A implica uma piora na situação de B, e ótimo no sentido de Kaldor Hicks porque o ganho de A é inferior à perda de B.

2 RAWLS, John. A theory of justice. 2. ed. Cambridge: Belknap, 1999. p. 68.

3 KLAPOW, Louis; SHAVELL, Steven. Why the legal system is less efficient than the income tax in redistributing income. Journal of Legal Studies, Chicago, v. 23, n. 2, p. 667-681, June, 1994. doi: 10.1086/467941.p. 674-675.

4 Outra versão do argumento da imprecisão acusa o direito privado de ser subinclusivo. Mesmo que todos os motoristas fossem ricos e todos os pedestres pobres, a ideia de redistribuir renda mediante um aumento das indenizações por acidentes de trânsito teria o seu impacto limitado, à primeira vista, aos motoristas e pedestres que de fato se envolvessem em acidentes.

5 KLAPOW, Louis; SHAVELL, Steven. Why the legal system is less efficient than the income tax in redistributing income. Journal of Legal Studies, Chicago, v. 23, n. 2, p. 667-681, June, 1994. doi: 10.1086/467941. A expressão double distortion foi cunhada por um 
tribuição defeituoso, como sugerem os argumentos da imprecisão e do escape contratual, mas também mais defeituoso, e inferior ao imposto de renda, o instrumento de redistribuição alternativo considerado pelos autores. Diferentemente dos argumentos antes referidos, o ADD também parece não se prender a características contingentes das regras de direito privado, ${ }^{6}$ dando assim a impressão de uma geral inferioridade do direito privado (em relação à tributação) como meio redistributivo.

O objetivo deste trabalho é singelo. Apresentamos abaixo uma revisão da literatura sobre o ADD dividida em duas partes, uma primeira, na qual o argumento é esmiuçado, e uma segunda, em que fazemos inventário conciso das críticas que lhe foram endereçadas. Não obstante o fato de a literatura ser relativamente abundante, o assunto, ainda é, de um modo geral, desconhecido do leitor brasileiro, ao qual o presente trabalho pode servir, então, como uma introdução. Além disso, embora exposições resumidas sobre o debate sejam encontradas em trabalhos estrangeiros sobre o tema, há contribuições recentes, como as de De Geest ${ }^{7}$ e Dagan, ${ }^{8}$ para as quais vale a pena chamar a atenção.

\section{O ARGUMENTO DA DUPLA DISTORÇÃO (ADD)}

Suponha que um governo queira ajudar os pobres, mas esteja em dúvida sobre como fazer isso. Será melhor elevar o imposto sobre a renda ou as indenizações pagas pelos ricos às vítimas de atos ilícitos? De modo mais geral, deve o governo perseguir seu objetivo redistributivo por meio da tributação ou de outras regras, como as do código civil (ou ambos)?

O argumento da dupla distorção (ADD) de Kaplow e Shavell ${ }^{9}$ é um argumento em favor da tributação (mais exatamente, do imposto sobre renda) como meio de redistribuição. Para compreendermos por que o imposto de renda é um meio de redistribuição preferível a outros, como a responsabilidade civil, consideramos o caso de duas regras, uma de imposto de renda, A, e outra de responsabilidade civil, B, cujo ônus sobre os ricos seja o mesmo. Trata-se de duas regras cujo custo esperado ${ }^{10}$ para cada cidadão rico é igual. A única diferença é que, em um caso, o custo em questão será arcado com o pagamento do tributo, e, no outro, mediante a imposição de uma regra de responsabilidade civil mais severa.

dos críticos do argumento. SANCHIRICO, Chris William. Taxes versus legal rules as instruments for equity: a more equitable view. Journal of Legal Studies, Chicago, v. 29, n. 2, p. 797-820, June, 2000. p. 799.

$6 \mathrm{O}$ argumento da imprecisão ignora, por exemplo, que uma regra de responsabilidade civil em favor dos pedestres pode ser definida de maneira a se aplicar somente quando o pedestre vítima de acidente é pobre, e que, graças ao seguro, o impacto da regra em questão pode não se limitar àqueles que de fato se envolvem em acidentes (LOGUE, Kyle; AVRAHAM, Ronen. Redistributing optimally: of tax rules, legal rules, and insurance. Tax Law Review, New York, v. 56, n. 2, p. 157-258, Winter, 2003. p. 184). O argumento do escape contratual, por sua vez, além de limitado, em geral, às relações contratuais, ignora que a livre estipulação de cláusulas nem sempre é possível, bem como que o efeito redistributivo de uma regra pode ser "horizontal", isto é, entre pessoas que estejam em posição análoga (por exemplo, entre consumidores de planos de saúde, ao invés de entre operadoras de planos de saúde e consumidores) (LOGUE, Kyle; AVRAHAM, Ronen. Redistributing optimally: of tax rules, legal rules, and insurance. Tax Law Review, New York, v. 56, n. 2, p. 157-258, Winter, 2003. p. 181).

7 DE GEEST, Gerrit. Removing rents: why the legal system is superior to the income tax at reducing income inequality. Disponível em: <http:/ ssrn.com/abstract=2337720 > . Acesso em: 25 maio 2014. doi: 10.2139/ssrn. 2337720 .

8 DAGAN, Tsilly. Pay as you wish: the global market for tax \& legal rules. Disponível em: <http://ssrn.com/abstract=2506051>. Acesso em: 25 maio 2014.

9 KLAPOW, Louis; SHAVELL, Steven. Why the legal system is less efficient than the income tax in redistributing income. Journal of Legal Studies, Chicago, v. 23, n. 2, p. 667-681, June, 1994. doi: 10.1086/467941.

10 Como o que interessa acima é a reação do cidadão rico à mudança na legislação, pode-se lançar mão da noção de custo esperado, ou custo provável. No caso da responsabilidade civil, o custo esperado é determinado pela probabilidade de ocorrência de um evento danoso mais a indenização a pagar em tal hipótese (presumindo-se que a aplicação da lei seja infalível). O custo esperado aumenta, portanto, com o aumento da indenização a pagar (mantendo-se a probabilidade do dano constante). A presunção acima é que, uma vez alterada a legislação, o incentivo para o trabalho dos cidadãos ricos é influenciado pelo aumento do custo esperado com a responsabilidade civil, ainda que, para alguns desses cidadãos (aqueles que não causarem dano algum), a mudança na legislação venha a se mostrar inócua. 
Kaplow e Shavell presumem que, se o custo esperado das regras A e B é o mesmo, o mesmo será também o seu efeito de desincentivo para o trabalho. ${ }^{11}$ Supõe-se, em outras palavras, que o incentivo para o trabalho seja uma função inversa do montante da renda de que o trabalhador é "expropriado", ${ }^{12}$ não importando se a base legal para tal expropriação é a legislação tributária ou o código civil. Sou encorajado a trabalhar menos sempre que a lei determinar que uma parte maior do produto do meu trabalho me seja tomada, não importando como, e é porque o desencorajamento, ao trabalho, acaba em geral reduzindo o montante total da produção que se chama isso de uma "distorção" comum aos dois modos (tributário e não tributário) de redistribuição de renda.

Pois bem, o cerne do ADD consiste em dizer que, embora as regras A e B tenham um efeito distorcivo comum, há uma outra distorção provocada exclusivamente pela regra de responsabilidade civil, B. Essa distorção adicional, a "segunda", é que confere vantagem ao imposto de renda como meio legal de redistribuição. Vejamos, então, em que consiste a referida distorção adicional causada pela regra B. Para tanto, imaginaremos que essa regra B institua um aumento percentual na indenização a pagar por ilícitos civis sempre que o causador do dano seja rico, e a vítima, pobre. Sigamos presumindo, tal como observado acima, que o custo esperado da regra em questão para os cidadãos ricos e o desestímulo para o trabalho (a primeira distorção) sejam os mesmos da regra A. A regra B tem, contudo, a particularidade de fazer com que o custo dela decorrente não seja necessariamente suportado com o pagamento de indenizações. Influenciados pela regra $\mathrm{B}$, alguns cidadãos ricos podem tomar medidas adicionais de precaução, a fim de evitar a ocorrência de atos ilícitos e, em consequência, o dever de indenizar. Deve-se considerar, portanto, que o custo que a regra B impõe aos ricos (o mesmo, repita-se, da regra A) pode estar relacionado tanto ao pagamento de indenizações quanto a medidas adicionais para prevenção de danos.

O problema da regra $\mathrm{B}$, segundo Kaplow e Shavell, reside justamente no fato de ela dar lugar às citadas medidas de precaução adicionais. ${ }^{13}$ Isso soa paradoxal, mas pode ser entendido se presumirmos que a precaução induzida pelo sistema legal antes da regra B é eficiente e levarmos em conta o que isso significa. O nível eficiente é atingido quando o custo marginal das medidas de precaução se iguala ao custo marginal esperado dos danos que tais medidas evitam. Esse é o ponto, em outras palavras, em que, para cada $\mathrm{R} \$ 1,00$ adicional investido em precaução, poupar-se-á exatamente $\mathrm{R} \$ 1,00$ em danos (considerando-se a magnitude desses danos e a probabilidade de que eles ocorram). Dizer que a precaução está além do nível eficiente significa, pois, que estão sendo tomadas medidas de precaução cujo custo é superior ao benefício (em termos de redução de danos).

Precisamos nos ater um pouco mais ao caso da precaução excessiva, já que a acusação contra a regra B é justamente o de ensejar essa distorção. Apreender melhor o significado de "excesso" leva-nos ao cerne do ADD. Muito bem, já vimos que, quando a precaução é reputada excessiva (segundo o critério da eficiência), é porque estão sendo tomadas medidas de precaução cujo custo é superior ao benefício. Exemplificando, então, suponhamos que, para cada $\mathrm{R} \$ 1,00$ que as medidas (excessivas) de precaução consomem, $\mathrm{R} \$ 0,80$ são poupados com redução de danos. Observe que o custo do dano é o custo para quem o sofre, de modo que, ao dizermos que as medidas de precaução adicionais levam a uma redução de danos de $R \$ 0,80$ para cada $R \$ 1,00$ investido, estamos dizendo que $R \$ 0,80$ (para cada $R$ \$ 1,00) é a perda de que certas pessoas (as vítimas em potencial) são poupadas graças à precaução. Qualquer que seja o modo como se traduz em moeda o custo do dano para as vítimas, essa monetarização parece ser essencial ao argumento, já que, sem ela, não se mostra possível aplicar o critério da eficiência mediante a comparação do custo e do benefício da precaução adicional.

11 KLAPOW, Louis; SHAVELL, Steven. Why the legal system is less efficient than the income tax in redistributing income. Journal of Legal Studies, Chicago, v. 23, n. 2, p. 667-681, June, 1994. doi: 10.1086/467941. p. 667-668.

12 O termo "expropriação" (assim como "redistribuição") sugere direitos de propriedade anteriores à tributação, o que é controverso, para dizer o mínimo. Uso-o acima sem essa conotação, simplesmente pela falta de um termo melhor.

13 Para simplificar, presumimos acima que a probabilidade do dano não é alterada pelo comportamento da vítima. Quando o contrário é verdadeiro, a regra B também causa ineficiência ao induzir as potenciais vítimas a tomarem pouca precaução. KLAPOW, Louis; SHAVELL, Steven. Why the legal system is less efficient than the income tax in redistributing income. Journal of Legal Studies, Chicago, v. 23, n. 2, p. 667-681, June, 1994. doi: 10.1086/467941. p. 669. 
Uma vez aceito que o custo do dano evitado é de $\mathrm{R} \$ 0,80$ (para cada $\mathrm{R} \$ 1,00$ investido em precaução), a acusação de ineficiência contra a regra B pode ser descrita do seguinte modo. Ao elevar o montante da indenização a pagar pelos ricos e induzi-los, com isso, a tomar medidas de precaução excessivas, a regra B de fato ajuda os pobres, presumindo-se que eles sejam os beneficiados pelas medidas de precaução adicionais. Essa ajuda, entretanto, é de $\mathrm{R} \$ 0,80$ (em danos evitados) para cada $\mathrm{R} \$ 1,00$ investido pelos ricos em precaução, o que leva a pensar que, ao invés da mudança no regime da responsabilidade civil, seria preferível elevar em um patamar equivalente o imposto de renda dos ricos e transferir aos pobres o adicional arrecadado. ${ }^{14}$

À primeira vista, o problema com a regra B é diferente do de políticas distributivas que transferem aos pobres outros bens a não ser o dinheiro e são, por isso, acusadas de paternalismo. Uma interpretação, ao menos, do ADD é que o pecado da regra B não é oferecer aos pobres maior segurança (graças ao incremento das medidas de precaução) ao invés de mais dinheiro, mas sim que essa segurança custa mais do que o que as potenciais vítimas de dano estão dispostas a pagar por ela. Não haveria mal em induzir o aumento das medidas de precaução se as grandezas do exemplo acima se invertessem, isto é, se, para cada $\mathrm{R} \$ 0,80$ investidos em precaução, $\mathrm{R} \$ 1,00$ em danos fosse poupado (caso no qual a regra B seria eficiente). A verdade, no entanto, é que, quando não há mercado para certos bens (como pode ser o caso de alguns dos bens que a responsabilidade civil protege), é difícil saber o quanto as pessoas estão dispostas a pagar por eles. Portanto, se a vantagem concedida por uma regra redistributiva não é monetária, pode ser impossível saber se o custo que essa regra impõe aos ricos é maior, menor ou igual que o benefício dado aos pobres.

Consideremos agora o caso de uma regra redistributiva (não tributária) B que tenha como consequência conferir aos favorecidos pela redistribuição uma vantagem exclusivamente monetária. Um exemplo pode ser o de uma regra sobre salário mínimo. Se o benefício concedido pela regra redistributiva é monetário, afasta-se, com isso, a hipótese de o seu custo ser superior (abstraindo-se, naturalmente, os custos administrativos) ao benefício que oferece. Cada $R \$ 1,00$ pago a mais pelos ricos como salário vale exatamente $R \$ 1,00$ para os pobres aos quais é transferido.

Decorre daí que regras de redistribuição não tributárias que confiram benefícios exclusivamente monetários não são vulneráveis ao ADD? Não. Essas regras são, de qualquer modo, distorcivas, devido ao fato de alterarem "preços". Nessa perspectiva, utilizamos o vocábulo "preço" entre aspas porque nem sempre se tratamos de bens que são, de fato, comprados e vendidos. O que regras de redistribuição contratuais e de responsabilidade civil ${ }^{15}$ fazem, na verdade, é modificar o incentivo para a realização das atividades sobre as quais incidem, tornando essas atividades menos atraentes do que de outro modo seriam. ${ }^{16}$ Ao instituir um salário mínimo, a regra trabalhista torna menos atraentes (aumentando-lhes, pois, o "preço") as atividades de produção que usam o trabalho mais intensivamente. Isso é tido como uma distorção devido ao fato de levar a uma oferta subótima (consideradas as preferências dos consumidores) dos bens cuja produção é desencorajada. No caso do imposto de renda, em contrapartida, essa distorção não se verifica devido à "neutralidade" do imposto, isto é, ao fato de o imposto de renda ser devido independentemente do modo (isto é, da espécie de atividade) pelo qual a renda é auferida.

Pode-se afirmar, em resumo, que a ineficiência adicional de que podem ser acusadas as regras redistributivas de direito privado verifica-se de duas maneiras. Em um caso, a ineficiência decorre do fato de se conceder aos pobres uma vantagem não monetária cujo custo, para os ricos, é de valor superior ao da vantagem em questão para os que a recebem, o que designarei doravante como "problema dos benefícios em espécie".

14 É evidente que, para cada $\mathrm{R} \$ 1,00$ que o imposto de renda custa aos ricos, menos de $\mathrm{R} \$ 1,00$ é transferido aos pobres. $\mathrm{O}$ ADD não ignora os custos administrativos da redistribuição tributária, mas presume que esses custos não sejam inferiores aos da redistribuição por outros meios. Voltarei a esse ponto na seção seguinte.

15 Isso vale também para regras tributárias que não apresentem a mesma generalidade ou "neutralidade" atribuída acima ao imposto de renda, tais como as que incidem sobre o consumo de certos bens.

16 Em alguns casos, o efeito da regra distributiva pode ser também o de tornar certas atividades artificialmente mais atraentes. Por exemplo, para as potenciais vítimas de dano, a regra que majora as indenizações pode tornar comportamentos de risco mais atraentes. 
No outro, o benefício dado é em dinheiro, mas a regra redistributiva causa distorção ao elevar os "preços" de certas atividades, o que se pode então referir como "problema de preços". ${ }^{17}$

\section{LIMITES DO ADD}

Nesta segunda seção, faço um inventário das críticas a que o ADD se sujeita. Vale lembrar, no entanto, que o ADD não é o único argumento contra o uso redistributivo do direito privado. Outros argumentos, como os da imprecisão e inocuidade, embora não mencionados a seguir, também devem ser considerados antes de uma palavra final sobre o tema. ${ }^{18}$

\subsection{Distorção do trabalho e lazer}

Como visto, uma presunção do ADD é que o desincentivo ao trabalho seja o mesmo independentemente de como os recursos são redistribuídos. Uma vez que isso seja falso e que regras redistributivas não tributárias induzam menos intensamente (ou até não induzam de todo) a substituição do trabalho por lazer, o ADD perde a sua força, e a questão sobre qual meio de redistribuição é superior passa a depender de uma comparação entre a ineficiência da distorção do trabalho e lazer causada pelo imposto de renda e a que decorre da regra de distribuição alternativa (a qual consiste em uma distorção do trabalho e lazer menor, nula ou até negativa mais a ineficiência relacionada aos problemas dos benefícios em espécie e dos preços). A questão se torna, então, empírica.

Pois bem, de que maneira regras redistributivas como as do direito privado podem desincentivar menos o trabalho do que as suas congêneres do imposto de renda? Uma possibilidade, aventada pelos próprios Kaplow e Shavell, ${ }^{19}$ é que regras redistributivas elevem o preço de certas atividades recreativas, desencorajando, assim, a substituição do trabalho pelo lazer. A regra de responsabilidade civil cogitada na seção anterior será um exemplo disso se, entre as atividades sobre as quais incida, estiverem atividades de lazer (como um passeio de iate). Isso não evita que essa regra possua os problemas antes mencionados, mas faz com que um juízo final acerca da sua eficiência quando comparada à do imposto de renda tenha de levar em conta a diferença entre o decréscimo de produção (menor, em se tratando da regra de responsabilidade civil) verificado em cada um dos casos.

17 Como deixa patente o exemplo da regra de responsabilidade civil examinado anteriormente, os dois problemas são distintos. Quando as indenizações a pagar são majoradas, há um desperdício do ponto de vista das pessoas beneficiadas pela regra, que ganham mais segurança quando prefeririam ter mais dinheiro (isto é, a segurança vale, para elas, menos do que custa) e outro decorrente da redução das atividades com potencial para causar dano, cujo preço relativamente a atividades inofensivas é elevado pela regra em questão. A distinção entre os problemas dos benefícios em espécie e dos preços é feita por Kaplow e Shavell no seguinte trecho, em que os autores se referem a uma regra que eleve a um patamar ineficiente as medidas de precaução tomadas por donos de iates. KLAPOW, Louis; SHAVELL, Steven. Why the legal system is less efficient than the income tax in redistributing income. Journal of Legal Studies, Chicago, v. 23, n. 2, p. 667-681, June, 1994. doi: 10.1086/467941. p. 680: "a ineficiência causada por essa regra terá três componentes: o cuidado excessivo é por definição mais custoso do que o dano prevenido; usar iates se torna mais caro, distorcendo escolhas entre andar de iate e outras atividades (por exemplo, jogar golfe); e a renda perde seu poder de compra para os ricos, distorcendo suas escolhas entre trabalho e lazer" (“( $(t) h e$ inefficiency caused by this rule will have three components: excessive care is by definition more costly than the harm prevented; yatching is made more expensive, which distorts choices between yachting and other activities (for example, playing golf); and income buys less for the rich, which distorts their labor-leisure choices'). 18 Assim também como a crítica formalista de Weinrib, segundo a qual o direito privado não deve ter qualquer fim político (como a igualdade ou a eficiência) que transcenda a estrita regulação de uma relação bilateral. WEINRIB, Ernst J. The idea of private law. Cambridge: Harvard, 1995.

19 KLAPOW, Louis; SHAVELL, Steven. Why the legal system is less efficient than the income tax in redistributing income. Journal of Legal Studies, Chicago, v. 23, n. 2, p. 667-681, June, 1994. doi: 10.1086/467941. p. 681; KAPLOW, Louis; SHAVELL, Steven. Should legal rules favor the poor?: clarifying the role of legal rules and the income tax in redistributing income. Journal of Legal Studies, Chicago, v. 29, n. 3, p. 821-835, June, 2000. p. 825-827. A respeito, v. também GEORGAKOPOULOS, Nicholas L. Exploring the Shavellian boundary: violations from judgment-proofing, minority rights, and signalling. Disponível em: <http://ssrn. com/abstract=932908>. Acesso em: 25 maio 2014. doi: 10.2139/ssrn.932908. p. 6-8. 
Outros argumentos no mesmo sentido, mas com premissas bastante diversas, são apresentados por Jolls, que se vale de estudos de psicologia para aventar diferenças entre os efeitos distorcivos de regras de redistribuição tributárias e de responsabilidade civil. ${ }^{20}$ Essas diferenças são atribuídas, em primeiro lugar, ao fato de a redistribuição baseada na responsabilidade civil depender da ocorrência do dano e ser, portanto, incerta. Admitindo-se uma tendência dos agentes a subestimar riscos (manifestação de um "otimismo irrealista" acerca do qual há robustas evidências), é então de esperar que o desincentivo ao trabalho provocado por uma regra de responsabilidade civil redistributiva seja menor do que o do imposto de renda, ainda que o montante redistribuído seja o mesmo nos dois casos. ${ }^{21}$ Outra cogitação é que a relação entre o trabalho e o imposto da renda seja particularmente saliente para os agentes, ensejando reação comportamental mais intensa à redistribuição baseada na tributação da renda do que a da feita por intermédio da responsabilidade civil. ${ }^{22}$

\subsection{Benefícios em espécie}

Afirmamos, na seção anterior, que um dos problemas de certas regras distributivas de direito privado consiste no fato de elas concedem vantagens não monetárias a um custo de valor superior ao que tais vantagens possuem para os que as recebem. Com o que aufere mediante a cobrança do imposto de renda, em contrapartida, o governo se torna capaz de promover a igualdade mediante a simples transferência de dinheiro, evitando, assim, o problema em questão. ${ }^{23}$

Essa vantagem do imposto de renda desaparece, no entanto, quando há razões para querer que os beneficiários da redistribuição recebam outros bens a não ser o dinheiro. ${ }^{24}$ Uma dessas razões é paternalista, a

20 JOLLS, Christine. Behavioral economic analysis of redistributive legal rules. Vanderbilt Law Review, v. 51, p. 1653-1677, 1998. É importante observar que o artigo de Jolls faz referência a estudos gerais acerca das peculiaridades comportamentais mencionadas acima, sem apresentar, portanto, evidências acerca dos impactos de diferentes regras de redistribuição.

21 JOLLS, Christine. Behavioral economic analysis of redistributive legal rules. Vanderbilt Law Review, Tennessee, v. 51, n. 6, p. 1653-1677, Nov. 1998. p. 1658-1663. Uma ressalva, feita pela própria Jolls é que a incerteza sobre o custo que a responsabilidade civil impõe a cada agente individualmente considerado pode ser eliminada pelo seguro. JOLLS, Christine. Behavioral economic analysis of redistributive legal rules. Vanderbilt Law Review, Tennessee, v. 51, n. 6, p. 1653-1677, Nov. 1998. p. 1663.

22 JOLLS, Christine. Behavioral economic analysis of redistributive legal rules. Vanderbilt Law Review, Tennessee, v. 51, n. 6, p. 1653-1677, Nov. 1998. p. 1670-1673. Lewinsohn-Zamir também levanta a hipótese de que o desincentivo ao trabalho decorrente de regras redistributivas de direito privado seja menor do que o das congênere do imposto de renda devido ao fato de as primeiras muitas vezes conferirem benefícios em espécie. LEWINSOHN-ZAMIR, Daphna. In defense of redistribution through private law. Minnesota Law Review, Minneapolis, v. 91, n. 2, p. 326-397, 2006. p. 352. A autora pouco diz, entretanto, sobre por que se deve esperar que o efeito distorcivo dos benefícios em questão seja menor do que o do dinheiro, limitando-se a supor que eles não sejam vistos como um acréscimo patrimonial pelas pessoas às quais são concedidos. Tampouco é considerado por Lewinsohn-Zamir o fato de que a redistribuição baseada no imposto de renda também pode prover benefícios em espécie ao invés de dinheiro.

23 É claro que o governo pode usar, e frequentemente usa, a receita do imposto de renda para ajudar os pobres de outra maneira que não pela simples entrega de dinheiro, o que acaba sujeitando a política redistributiva baseada na tributação ao problema dos benefícios em espécie. A diferença é que a transferência de dinheiro permanece sempre possível quando a redistribuição se vale do imposto de renda, enquanto que, no caso das regras de direito privado, as vantagens conferidas são às vezes por natureza não monetárias.

24 Note que o ponto referido acima nada tem a ver com a razão pela qual alguém faz jus à redistribuição. A despeito do que afirmam Blumkin e Margalioth, é um erro entender que o ADD somente tem validade quando a única razão para transferir recursos do cidadão X para o cidadão Y é a diferença de renda ou riqueza entre ambos. BLUMKIN, Tomer; MARGALIOTH, Yoram. On the limits of redistributive taxation: establishing a case for equity-informed legal rules. Virgina Tax Review, v. 25, n. 1, p. 1-29, June, 2005. p. 18. O fato de haver uma razão distinta para a redistribuição - por exemplo, a de que Y está em pior situação de saúde do que $\mathrm{X}$ - não significa que haja uma solução redistributiva melhor do que transferir uma certa quantia em dinheiro de $\mathrm{X}$ para $\mathrm{Y}$ e, portanto, não afasta o problema dos benefícios não monetários. Fazer com que $\mathrm{X}$ arque com as despesas de um tratamento de saúde para $\mathrm{Y}$ pode ter o mesmo inconveniente da regra de responsabilidade civil mencionado acima, isto é, conceder a Y uma vantagem cujo custo para X é superior ao valor que a mesma vantagem tem para Y. A fim de que a natureza da razão redistributiva (isto é, da razão para tirar recursos de $\mathrm{X}$ e dá-los a Y) tenha alguma implicação para o problema dos benefícios não monetários, é preciso que essa razão seja tal que somente justifique a redistribuição caso a vantagem conferida a Y seja não monetária. Por exemplo, uma regra de igualdade de oportunidades pode não apenas tratar algo diverso da diferença de riqueza (a desigualdade de oportunidades) como razão para uma redistribuição contra X e em favor de $\mathrm{Y}$, como também somente justificar essa redistribuição caso ela ocorra na "moeda" das oportunidades (isto é, mediante uma redução das oportunidades de X e um correspondente aumento das de Y). Por certo, em tal hipótese, não se poderia reputar a transferência de dinheiro de X para Y por meio da tributação como uma solução 
qual pode tornar preferível uma legislação que garanta certa cobertura aos contratantes de planos de saúde preferível, como meio redistributivo, a uma política de transferência de dinheiro baseada na tributação.

É também possível que a concessão de um benefício em espécie seja superior a transferências em dinheiro devido a algum problema de ação coletiva que acometa os beneficiários da redistribuição. Por exemplo, pessoas com deficiência podem estar dispostas a pagar o necessário para que lhe sejam providas acomodações especiais no lugar de trabalho. Como, no entanto, essas acomodações têm características de um bem público (isto é, são de uso não excludente), é bem possível que, a depender das decisões individuais dos envolvidos, elas acabem não sendo oferecidas. O interessante, nesses casos, é não só que o problema dos benefícios em espécie de fato não existe (porque os beneficiários da redistribuição recebem uma vantagem pela qual estão dispostos a pagar o que custa), como também, ao ajudar a superar o mencionado problema de ação coletiva, uma regra redistributiva que garanta acomodações especiais é, ao menos em certo sentido, superior, em termos de eficiência, a uma regra congênere de transferência de dinheiro.

Vale ressaltar que, ao menos nas hipóteses consideradas neste estudo, o fato de certas regras redistributivas de direito privado não se sujeitarem ao problema dos benefícios em espécie (porque a concessão desses benefícios se justifica, seja por razões paternalistas, seja de eficiência, em face de problemas de ação coletiva) não chega a constituir argumento em defesa da superioridade do direito privado como meio de redistribuição. Políticas de transferência de benefícios não monetários, como tratamento de saúde ou acomodações especiais para pessoas com deficiência, podem ser mantidas com recursos advindos da tributação, sem depender, portanto, de instrumentos característicos do direito privado, tais como regras limitadoras da liberdade contratual. Somente o que se pode dizer, nos casos em que há razões paternalistas ou relacionadas a problemas de ação coletiva para que a redistribuição se dê mediante a concessão de benefícios em espécie, é que desaparece um dos argumentos em favor da redistribuição baseada no imposto de renda.

Algo diverso se dá quando a justificativa para que a redistribuição não se dê mediante a entrega de dinheiro é que o bem a redistribuir está entre aqueles que o dinheiro não pode comprar. ${ }^{25}$ Quando a redistribuição tem por objeto um bem assim, o direito privado pode se mostrar, de fato, um instrumento preferível à tributação. Isso ocorre quando o bem em questão é daqueles que somente as regras de direito privado podem prover.

Por exemplo, considere-se que o bem em jogo seja a oportunidade para o trabalho, e que esse bem só esteja corretamente distribuído, segundo nossos parâmetros de justiça, caso os candidatos a postos de trabalho não sejam vítimas de certas práticas discriminatórias. A igualdade de oportunidades — ou a proteção contra a discriminação — não é um bem que se pode comprar. Não se pode esperar que as potenciais vítimas de discriminação paguem para ter um tratamento equânime, porque esse é um direito que geralmente não se comercializa. Além disso, mesmo que o direito em questão esteja disponível para compra (isto é, que os empregadores aceitem se abster, mediante pagamento, das práticas discriminatórias) o fato de que alguém ter de pagar para não sofrer discriminação é, provavelmente, ele mesmo atentatório contra a regra da igualdade de oportunidade (as oportunidades não são iguais se alguns precisam pagar para ter oportunidades iguais). Em tais circunstâncias, portanto, uma política redistributiva que procurasse compensar monetariamente as vítimas de discriminação fracassaria em dar a essas pessoas aquilo que thes é moralmente devido (que é, como estou presumindo, a igualdade de oportunidades em si, e não algum benefício a ela relacionado), porque o que lhes é devido é algo que elas não podem comprar.

Um caso particular em que o bem a redistribuir não pode ser comprado, e no qual, portanto, o direito privado pode se mostrar um meio de redistribuição superior à tributação, é aquele no qual se atribui relevância

redistributiva superior, já que, ao ter lugar de outra maneira que não pela supressão das diferenças de oportunidades, a redistribuição simplesmente deixaria de se justificar.

25 BLUMKIN; Tomer; MARGALIOTH, Yoram. On the limits of redistributive taxation: establishing a case for equity-informed legal rules. Virgina Tax Review, v. 25, n. 1, p. 1-29, June, 2005. p. 14-18; GEORGAKOPOULOS, Nicholas L. Exploring the Shavellian boundary: violations from judgment-proofing, minority rights, and signalling. Disponível em: <http://ssrn.com/abstract=932908>. Acesso em: 25 maio 2014. doi: 10.2139/ssrn.932908. p. 8-12. 
à força simbólica, ou expressiva, da regra redistributiva. ${ }^{26}$ Todo o restante sendo igual, é plausível que se deva preferir a regra redistributiva com melhor impacto sobre a autoestima (e, portanto, o bem-estar) daqueles a quem favorece. $\mathrm{O}$ argumento do valor expressivo nega, portanto, que o dinheiro (ou outros bens que o dinheiro pode comprar) seja o único bem relevante do ponto de vista da distributiva. Ao invés disso, esse argumento inclui entre os bens cuja distribuição é relevante a autoestima, o que torna possível que a melhor política redistributiva seja constituída também por regras não tributárias que, embora menos aptas à redistribuição de bens materiais, amenizem o potencial negativo da redistribuição sobre a autoestima. Tudo isso pressupõe, por óbvio, não apenas que a autoestima seja relevante, mas também que regras redistributivas de direito privado sejam ocasionalmente menos perniciosas à autoestima do que as do imposto de renda. ${ }^{27}$

\subsection{Propinas}

Um argumento apresentado recentemente em favor do uso redistributivo das regras de direito privado é o argumento das "propinas" (rents). ${ }^{28}$ Propinas se definem como "ganhos que não seriam auferidos em uma economia perfeitamente competitiva e transparente." ${ }^{29}$ O cerne do argumento de De Geest é simples. Quando se trata de propinas, a tributação da renda tem uma atuação ex post, já que, ao invés de fazer cessar a prática por meio da qual a propina é obtida, limita-se a atacar seus resultados, expropriando parte do ganho excessivo. Além disso, as regras tributárias geralmente são inaptas a diferenciar a parte da renda total de uma pessoa correspondente à propina, a fim de onerá-la mais pesadamente. Em contrapartida, regras não tributárias, como as regras antitruste, ${ }^{30}$ atuam preventivamente ou ex ante, impedindo a prática ensejadora da propina (no caso, a concertação anticoncorrencial). ${ }^{31}$ Admitindo-se que haja uma razão para considerar a

26 KEREN-PAZ, Tsachi. Torts, egalitarianism and distributive justice. Hampshire: Ashgate, 2007. p. 48.

27 O argumento acima tem certa similitude com o que é usado por Lewinsohn-Zamir, a qual situa as regras distributivas, de acordo com o seu efeito sobre o bem-estar das pessoas favorecidas, em um contínuo que vai do "prêmio" (reward) à "humiliação" (bumiliation). LEWINSOHN-ZAMIR, Daphna. In defense of redistribution through private law. Minnesota Law Review, Minneapolis, v. 91, n. 2, p. 326-397, 2006. p. 331. Diferentemente de atentar apenas para o impacto psíquico dos diferentes instrumentos legais de redistribuição, no entanto, Lewinsohn-Zamir tem em vista a relação entre redistribuição e uma concepção objetiva de bem-estar. Graças a isso, seu argumento em defesa das regras redistributivas de direito privado não é contingente do efeito psicológico dessas regras. Segundo LEWINSOHN-ZAMIR, Daphna. In defense of redistribution through private law. Minnesota Law Review, Minneapolis, v. 91, n. 2, p. 326-397, 2006. p. 349-350: "se nossa meta é redistribuir bem-estar definido objetivamente, e não apenas a renda como meio de satisfazer preferências atuais, então regras legais redistributivas são por natureza mais apropriadas para a tarefa do que tributos e políticas de transferência de dinheiro. Regras de direito privado emitem uma mensagem sobre as coisas que vale a pena ter e diretamente provê os bens tidos como necessários para o bem-estar das pessoas" "“iiff our aim is to redistribute well-being, objectively defined, rather than just income as a means for actual preference satisfaction, then redistributive legal rules are by their very nature better suited to the task than taxes and money transfers. Private law rules convey a message as to the things worth having and directly provide for the goods deemed necessary for people's well-being"). Lewinsohn-Zamir também apresenta, não obstante, um argumento sobre qual pode ser, de um modo geral, a vantagem psicológica das regras redistributivos de direito privado, a saber, a de que essas regras são endereçadas a classes de pessoas (como as dos consumidores ou vítimas de acidentes de trânsito) que não correspondem perfeitamente às dos pobres ou cidadãos em pior situação, o que faz com que, no caso do uso redistributivo do direito privado (comparado, por exemplo, a políticas assistenciais que definam seus beneficiários com base na renda), a motivação para ajudar os pobres seja menos explícita. LEWINSOHNZAMIR, Daphna. In defense of redistribution through private law. Minnesota Law Review, Minneapolis, v. 91, n. 2, p. 326-397, 2006. p. 359-360. Com isso, Lewinsohn-Zamir curiosamente transforma, pois, o argumento da imprecisão em um argumento a favor da redistribuição por intermédio do direito privado.

28 DE GEEST, Gerrit. Removing rents: Why the legal system is superior to the income tax at reducing income inequality. Disponível em: <http://ssrn.com/abstract=2337720>. Acesso em: 25 maio 2014. doi: 10.2139/ssrn.2337720. Em português, o termo "rent" é usualmente traduzido como "renda". Ao invés de "renda", porém, prefiro acima "propina" pela simples necessidade de uma palavra diferente da usada para traduzir o termo "income".

29 DE GEEST, Gerrit. Removing rents: why the legal system is superior to the income tax at reducing income inequality. Disponível em: <http://ssrn.com/abstract=2337720>. Acesso em: 25 maio 2014. doi: 10.2139/ssrn.2337720. p. 4: "(P)rofits that would not have being earned in a perfectly competitive and transparent economy."

30 Além da legislação antitruste, De Geest afirma que as propinas podem ser combatidas por regras mais frequentemente vistas como pertencentes ao âmbito do direito privado, como as regras sobre propriedade intelectual e de proteção ao consumidor. DE GEEST, Gerrit. Removing rents: why the legal system is superior to the income tax at reducing income inequality. Disponível em: $<$ http://ssrn.com/abstract=2337720>. Acesso em: 25 maio 2014. doi: 10.2139/ssrn.2337720. p. 20-24; 26.

31 De Geest descreve a vantagem do controle ex ante (não tributário) da propina sobre o controle ex post (tributário) como uma 
propina mais odiosa, do ponto de vista da justiça distributiva, do que a renda auferida em um mercado perfeitamente competitivo, regras como a da legislação antitruste podem ser consideradas, pois um instrumento de redistribuição mais preciso do que as regras tributárias. ${ }^{32}$

O próprio De Geest admite, no entanto, que é duvidoso se a existência de propinas é de fato perniciosa para a igualdade. ${ }^{33} \mathrm{~A}$ resposta a essa questão depende, por um lado, da concepção de justiça distributiva que se queira aplicar e, por outro, de outras características relevantes (como, por exemplo, a riqueza total) dos sujeitos envolvidos. Um mundo sem propinas é um no qual as rendas são resultado de mercados perfeitamente transparentes e competitivos. Se esse mundo é mais ou menos igualitário do que um mundo com propinas, é algo que parece difícil determinar a priori.

Outra ressalva é a que se refere à relação entre o argumento de De Geest e o ADD. Se o ADD for entendido como um argumento sobre a comparação entre o imposto de renda e regras não tributárias de redistribuição ex post, então o argumento da propina não é um argumento contrário ao ADD, porque não afirma que regras não tributárias como as do direito privado sejam um meio superior ao imposto de renda para realizar tal redistribuição. ${ }^{34} \mathrm{O}$ que o argumento da propina nega é que o imposto de renda seja um instrumento mais apropriado para qualquer redistribuição, incluindo a que tem lugar mediante a repressão a práticas que engendrem propinas (isto é, a redistribuição ex ante). ${ }^{35}$

\subsection{A alternativa tributária paretianamente superior}

Uma das afirmações de Kaplow e Shavell em seu trabalho sobre o ADD é que, tendo em vista a ineficiência provocada por regras de direito privado, o imposto de renda se mostra uma alternativa redistributiva paretianamente superior, isto é, que melhora a situação de ao menos uma pessoa sem piorar a de quem quer que seja. ${ }^{36}$ Pode-se dizer que parte da força do ADD está, então, em apresentar o imposto de renda como instrumento de redistribuição que, quando comparado a outros, como as regras de direito privado, não é desvantajoso para ninguém.

\footnotetext{
vantagem informativa. DE GEEST, Gerrit. Removing rents: why the legal system is superior to the income tax at reducing income inequality. Disponível em: <http://ssrn.com/abstract=2337720>. Acesso em: 25 maio 2014. doi: 10.2139/ssrn.2337720. p. 9-10. Enquanto o controle expost requer informação sobre a propina que cada contribuinte amealhou individualmente, para o controle $e x$ ante é suficiente a informação sobre o montante de propina agregado. Retornemos, para ilustrar, ao exemplo da legislação antitruste: para fazer uma análise de custo-benefício sobre a conveniência de combater a formação de cartéis, a administração pública precisa tão-somente de informação sobre os custos globais decorrentes da prática em questão, e não de informação sobre a magnitude do ganho de cada uma das pessoas envolvidas.

32 DE GEEST, Gerrit. Removing rents: why the legal system is superior to the income tax at reducing income inequality. Disponível em: < http://ssrn.com/abstract=2337720>. Acesso em: 25 maio 2014. doi: 10.2139/ssrn.2337720. p. 8-10. Uma razão de eficiência para tratar diferenciadamente a propina e o restante da renda é que a propina é em geral duplamente distorciva. Ela é comparável a um imposto sobre o consumo, cuja receita não é, entretanto, apropriada pelo estado, mas por um particular. Assim sendo, a propina é não só um desincentivo ao trabalho (com exceção das hipóteses em que incide sobre o lazer) como reduz a demanda pelos bens sobre os quais é cobrada. DE GEEST, Gerrit. Removing rents: why the legal system is superior to the income tax at reducing income inequality. Disponível em: <http://ssrn.com/abstract=2337720>. Acesso em: 25 maio 2014. doi: 10.2139/ssrn.2337720. p. 11.

33 DE GEEST, Gerrit. Removing rents: why the legal system is superior to the income tax at reducing income inequality. Disponível em: <http://ssrn.com/abstract=2337720>. Acesso em: 25 maio 2014. doi: 10.2139/ssrn.2337720. p. 30.

34 DE GEEST, Gerrit. Removing rents: why the legal system is superior to the income tax at reducing income inequality. Disponível em: <http://ssrn.com/abstract=2337720>. Acesso em: 25 maio 2014. doi: 10.2139/ssrn.2337720. p. 32-33.

35 DE GEEST, Gerrit. Removing rents: why the legal system is superior to the income tax at reducing income inequality. Disponível em: <http://ssrn.com/abstract=2337720>. Acesso em: 25 maio 2014. doi: 10.2139/ssrn.2337720. p. 33.

36 KLAPOW, Louis; SHAVELL, Steven. Why the legal system is less efficient than the income tax in redistributing income. Journal of Legal Studies, Chicago, v. 23, n. 2, p. 667-681, June, 1994. doi: 10.1086/467941. p. 669.
} 
Uma crítica ao ADD diz respeito a essa afirmação. ${ }^{37}$ A pretensão de que o imposto de renda seja uma alternativa redistributiva paretianamente superior às regras de direito privado depende ou da presunção de uma certa homogeneidade entre os agentes, ou de uma estimativa irrealista acerca da aptidão da legislação tributária para obter informações sobre os contribuintes e tratá-los diferentemente de acordo com essas informações.

Retomemos o exemplo da regra de responsabilidade civil (B) que majora a indenização a pagar se o réu é rico e o autor da ação, pobre. Para afirmar que um aumento do imposto de renda (regra A) para os ricos, combinado com políticas de transferência em favor dos pobres, é uma alternativa paretianamente superior à regra em questão, podemos simplesmente presumir que o impacto da regra B seja o mesmo entre ricos e pobres, de tal modo que esse impacto possa ser replicado (salvo o desperdício correspondente à precaução excessiva) por uma elevação uniforme do imposto de renda a ser pago pelos ricos acompanhada de uma política de transferência, também uniforme, em favor dos pobres. No entanto, presumir que o impacto da regra B seja uniforme entre ricos e pobres significa presumir, de maneira um tanto irrealista, que as diferenças entre os cidadãos de cada uma das classes não ocasionem variações no efeito da regra sobre cada um. Considere, ao contrário, que diferenças individuais determinem variações no impacto da regra em exame, como na hipótese em que alguns ricos sejam mais desastrados do que outros e, consequência, mais suscetíveis a causar acidentes - ou em que alguns pobres sejam mais vulneráveis a acidentes do que outros e estejam, assim, mais propensos a serem beneficiados por uma regra de responsabilidade redistributiva. Em tais hipóteses, um aumento do imposto de renda que realize uma redistribuição sem distinções de recursos dos ricos para os pobres não é uma alternativa paretianamente superior à responsabilidade civil, já que, em comparação com um mundo no qual parte da redistribuição se faça mediante o pagamento de indenizações, algumas pessoas (os ricos com menor chance de causar acidentes na primeira hipótese, e os pobres com maior chance de sofrê-los na segunda) estarão em pior situação.

Quando os agentes são heterogêneos, o imposto de renda somente se mostra um meio de redistribuição paretianamente superior, quando comparado à regra de direito privado em relação à qual a heterogeneidade se verifica, caso sua incidência seja modulada de tal maneira a replicar as variações de impacto do direito privado. Nas hipóteses aventadas acima, isso requereria, respectivamente, elevar mais o imposto dos ricos com maior probabilidade de causar acidentes e transferir uma quantidade maior de recursos para os pobres com maior probabilidade de sofrê-los. Como observam Logue e Avraham, entretanto, a tarefa de desenhar uma política de tributação e transferência em tais moldes demanda informações de que os órgãos governamentais encarregados habitualmente não dispõem..$^{38}$

Em suma, afastadas certas presunções irrealistas, é falso que o imposto de renda seja uma alternativa paretianamente superior ao direito privado como meio redistributivo. Pode-se indagar, no entanto, o quão relevante para o debate é essa conclusão, tendo em vista a dificuldade de qualquer reforma legal atender ao requisito da superioridade paretiana. ${ }^{39} \mathrm{O}$ que pode ser mais grave do que contrariar esse requisito é o eventual fato de a redistribuição do imposto de renda se mostrar insensível a características individuais relevantes, que constituam, segundo a justiça, razões para dispensar às pessoas em questão um tratamento diferenciado. Admitindo-se que a solução eficiente seja o pagamento de uma indenização de valor igual ao do dano, uma regra de responsabilidade civil eficiente seria suficiente, por si só, para prover às pessoas mais propensas a

37 LOGUE, Kyle; AVRAHAM, Ronen. Redistributing optimally: of tax rules, legal rules, and insurance. Tax Law Review, New York, v. 56, n. 2, p. 157-258, Winter, 2003. p. 191-193; AVRAHAM, Ronen; FORTUS; David; LOGUE, Kyle. Revisiting the roles of legal rules and tax rules in income distribution: a response to Kaplow and Shavell. Iowa Law Review, Iowa City, v. 89, n. 4, p. 11251158, Apr. 2004.; SANCHIRICO, Chris William. Deconstructing the new efficiency rationale. Cornell Law Review, New York, v. 86, n. 6, p. 1003-1089, Jul. 2001. p. 1057-1064.

38 LOGUE, Kyle; AVRAHAM, Ronen. Redistributing optimally: of tax rules, legal rules, and insurance. Tax Law Review, New York, v. 56, n. 2, p. 157-258, Winter, 2003. p. 192-193.

39 O que vale em um sentido valeria também no outro, caso o desperdício de recursos decorrente do uso redistributivo do direito privado fosse inferior ao da tributação. Também parece virtualmente impossível forjar um regime de responsabilidade civil que, dando conta das diferenças entre os agentes, consiga replicar os resultados da legislação sobre o imposto de renda. 
sofrer danos um montante proporcionalmente maior do total das indenizações. Isso, contudo, talvez não baste, isto é, talvez a justiça exija conceder a essas pessoas uma quantidade de recursos ainda maior do que a decorrente da aplicação da regra eficiente. Em tal caso, a substituição da responsabilidade civil pelo imposto de renda como meio de redistribuição não apenas desatenderia ao requisito da superioridade paretiana como, ao menos em princípio, seria indesejável do ponto de vista da justiça. ${ }^{40}$

\subsection{Custos administrativos}

O ADD tem em vista apenas os custos relacionados aos efeitos comportamentais de diferentes instrumentos legais redistributivos, sem considerar os custos "administrativos", uma categoria abrangente na qual se incluem tanto os custos incorridos por autoridades para aplicação das regras como pelos particulares para cumpri-las. Mesmo que o ADD seja, portanto, em si mesmo correto, uma conclusão definitiva sobre se o imposto de renda é um meio de redistribuição superior, em termos de eficiência, ao direito privado depende de uma comparação entre os custos administrativos envolvidos em cada caso. ${ }^{41}$

\subsection{Entraves políticos}

Outra ressalva ao ADD é que de nada serve demonstrar que o imposto de renda é, em tese, o melhor meio legal se o caminho político para o uso da tributação com fins redistributivos estiver obstruído. ${ }^{42} \mathrm{Em}$ um mundo com entraves políticos a que a justiça se realize por intermédio da tributação, regras redistributivas de direito privado podem, apesar de ineficientes, mostrar-se atraentes.

A ressalva recém feita se enfraquece, no entanto, se considerarmos que a falta de disposição dos órgãos políticos para reformar a legislação tributária é também provavelmente um empecilho ao uso redistributivo do direito privado. Para acreditar no contrário, seria preciso admitir que haja uma boa razão para que, embora se recusem a lançar mão da tributação para a promoção da igualdade, os legisladores não apresentem a mesma resistência quando se trata de perseguir o referido objetivo de outras maneiras. Outra possibilidade é que regras redistributivas de direito privado acabem instituídas graças a decisões de outros órgãos que não os incumbidos de alterar a legislação tributária. No Brasil, por exemplo, enquanto a definição das alíquotas do imposto de renda compete exclusivamente aos órgãos legislativos, o direito privado é por vezes modificado de maneira substancial pelos juízes. Isso suscita, é claro, uma questão sobre a repartição de competências entre os órgãos do Estado que não é objeto deste estudo. ${ }^{43}$

40 Um exemplo de Logue e Avraham é o de pessoas acometidas por doenças de causas exclusivamente genéticas, como a síndrome de Huntington. Um direito contratual eficiente pode se mostrar injusto para essas pessoas ao permitir, por exemplo, que elas recebam tratamento diferenciado de empregadores e companhias seguradoras. Para resolver o problema, pode-se então lançar mão de uma solução no âmbito do próprio direito privado, a proibição da discriminação, ou de uma solução tributária, como a redução do imposto a pagar pelas pessoas portadoras da doença. Para Logue e Avraham, entretanto, admitindo-se que não deva haver discriminação contra as pessoas em questão, o resultado justo é muito mais fácil de alcançar por meio do direito privado do que da tributação, para a qual seria preciso dispor de informação sobre não apenas quem são as vítimas da doença, mas também o montante de recursos adicionais de que elas necessitam para acabar em situação análoga à que decorreria do fim da discriminação por empregadores e seguradoras. LOGUE, Kyle; AVRAHAM, Ronen. Redistributing optimally: of tax rules, legal rules, and insurance. Tax Law Review, New York, v. 56, n. 2, p. 157-258, Winter, 2003. p. 213-214.

41 BLUMKIN; Tomer; MARGALIOTH, Yoram. On the limits of redistributive taxation: establishing a case for equity-informed legal rules. Virgina Tax Review, v. 25, n. 1, p. 1-29, June, 2005. p. 11-14.

42 KEREN-PAZ, Tsachi. Torts, egalitarianism and distributive justice. Hampshire: Ashgate, 2007.p. 53-54.

43 KLAPOW, Louis; SHAVELL, Steven. Why the legal system is less efficient than the income tax in redistributing income. Journal of Legal Studies, Chicago, v. 23, n. 2, p. 667-681, June, 1994. doi: 10.1086/467941. p. 675. Kaplow e Shavell parecem sugerir que uma atuação das cortes em favor da justiça redistributiva acabaria contra-atacada por legisladores contrários a esse objetivo. Pode ser, mas vale considerar que o argumento dos entraves políticos pode dizer respeito não tanto a uma aversão à igualdade, mas, simplesmente, à paralisia dos órgãos legislativos. Um parlamento pode se manter inerte a mudanças progressivas da jurisprudência, não porque está de acordo com essas medidas, mas sim porque, mesmo se opondo, encontra-se paralisado. 
O problema dos entraves políticos também pode ser entendido de uma outra maneira, como dificuldade não para que sejam instituídas regras de redistribuição, mas para fazer com que essas regras sejam cumpridas. À medida que o ADD prova a superioridade do imposto de renda como meio redistributivo, prova-a para circunstâncias ideais nas quais a legislação é invariavelmente obedecida ou para circunstâncias (não ideais) nas quais a disposição a cumprir regras pertencentes a diferentes áreas da legislação se mantenha constante. Contudo, se houver uma propensão maior a atender a certas regras redistributivas do que a outras, uma razão de eficácia pode tornar preferível outro meio de redistribuição que não o imposto de renda.

\subsection{Fuga da jurisdição}

Uma nova perspectiva para o debate sobre o meio legal mais adequado de redistribuição é defendida por Galle ${ }^{44} \mathrm{e}$, mais recentemente, Dagan..$^{45}$ Esses autores chamam a atenção para um ponto totalmente ignorado por Kaplow e Shavell em seus trabalhos sobre o ADD, a saber, o de que, entre os possíveis efeitos comportamentais de uma regra redistributiva, estão providências tomadas pelos agentes para submeter-se a outra jurisdição e fugir, com isso, da aplicação da regra em questão. Por exemplo, o efeito de uma regra majorando o imposto de renda no Brasil pode ser o de fazer com que alguns contribuintes tomem medidas a fim de escapar à lei fiscal brasileira para se sujeitar à de algum outro país.

Considerar a possibilidade de fuga da jurisdição altera substancialmente a análise sobre o melhor meio de jurisdição. Mesmo que seja inferior sob outros pontos de vista, uma regra redistributiva A pode se mostrar, ao fim e ao cabo, superior a uma outra regra B se a probabilidade de fuga da jurisdição for menor sob a primeira do que sob a segunda, já que, quanto maior a referida probabilidade, mais ineficaz, potencialmente, é o instrumento redistributivo em questão.

Implícita no que acaba de ser afirmado, e fundamental para estimar a importância das contribuições de Galle (2010) e Dagan (2014) para o debate, é a ideia de que a probabilidade de fuga da jurisdição não é necessariamente constante. Segundo Dagan, dois fatores determinam que essa probabilidade varie: o custo das medidas necessárias para que um agente se submeta a uma jurisdição diversa e a magnitude das diferenças entre uma legislação e outra. ${ }^{46}$ Em relação ao primeiro fator, seria preciso avaliar, tendo em vista o debate ora sob exame, o custo a incorrer pelos agentes para fugir à legislação tributária e ao direito privado. ${ }^{47} \mathrm{Em}$ relação ao segundo, a magnitude das diferenças entre as legislações de cada país é importante porque dela depende o eventual benefício que a fuga da jurisdição proporciona. De nada adianta a fuga da jurisdição poder ocorrer a um baixo custo se as leis de diferentes países ${ }^{48}$ são bastante similares, tornando desprezível o benefício da mudança.

\section{Conclusão}

A literatura crítica ao ADD constitui bom guia para os que se interessam pelo tema de um direito privado igualitário. Seguindo a ordem das considerações feitas acima, deveríamos então procurar determinar:

44 GALLE, Brian. Is local consumer protection law a better redistributive mechanism than the tax system? New York University Annual Survey of American Law, New York, v. 65, p. 525-544, june 2009.

45 DAGAN, Tsilly. Pay as you wish: the global market for tax \& legal rules. Disponível em: <http://ssrn.com/abstract=2506051>. Acesso em: 25 maio 2014.

46 DAGAN, Tsilly. Pay as you wish: the global market for tax \& legal rules. Disponível em: $<$ http://ssrn.com/abstract=2506051>. Acesso em: 25 maio 2014. p. 5-7.

47 O custo da fuga pode variar inclusive no interior do direito privado, isto é, pode não ser o mesmo em setores diferentes do direito privado, como os dos contratos e da responsabilidade civil.

48 A referência a "países", acima, é uma simplificação. Pode haver fuga da jurisdição no interior de um mesmo país (quando há variação da legislação aplicável a diferentes regiões de um mesmo país) e fuga para jurisdições pertencentes a país algum (como no caso em que contratantes decidam se submeter a uma lex mercatoria). 
a) se, e quando, o desincentivo ao trabalho (a distorção do trabalho e lazer) decorrente de regras redistributivas de direito privado é menor do que o do imposto de renda;

b) se, e quando, razões paternalistas e problemas de ação coletiva minoram a ineficiência do direito privado como meio redistributivo;

c) quais, se algum, entre os bens que o dinheiro não pode comprar devem ser redistribuídos e só podem ser redistribuídos pelo direito privado;

d) se, e em que casos, o combate às propinas promove a igualdade;

e) se, e em que casos, as regras redistributivas de direito privado podem ter um impacto diferenciado ao mesmo tempo relevante, do ponto de vista da justiça, e difícil de reproduzir por outras áreas da legislação;

f) se, e em que casos, os custos administrativos da redistribuição são menores para o direito privado do que para outras áreas;

g) se, e em que casos, os entraves políticos à redistribuição baseada no direito privado são comparativamente menores, e se, e em que medida, é aceitável fazer uso do direito privado nessas circunstâncias;

h) se, e em que casos, as regras redistributivas de direito privado correm menos risco (sempre comparativamente falando) de se tornarem ineficazes devido à fuga da jurisdição.

Embora as linhas de investigação correspondentes a cada um desses itens sejam, de um modo geral, multidisciplinares, é fácil perceber que a contribuição a esperar de certas áreas do conhecimento é maior em alguns casos do que em outros. A psicologia tem papel imprescindível para avaliar hipóteses sobre o efeito de desincentivo ao trabalho das regras redistributivas de direito privado (item "a"). A filosofia política deve ter algo a dizer sobre o padrão a seguir na redistribuição, sobre a motivação paternalista para as transferências de bens não monetários (item "b), sobre a questão, mais geral, dos bens a redistribuir (entre eles, bens que o dinheiro não pode comprar) (item “c) e sobre razões para a redistribuição para as quais o imposto de renda e outras áreas da legislação que não o direito privado costumem se mostrar insensíveis (item "e"). A economia é útil para mensurar o impacto de problemas de ação coletiva (item "b"), das propinas (item "d"), dos custos administrativos comparados (item " $\mathrm{f}$ ”) e da fuga da jurisdição provocada por diferentes instrumentos legais de redistribuição (item " $h$ "). A ciência política e a sociologia do direito ajudam a estimar os entraves políticos, enquanto que a teoria do estado se ocupa da divisão de competências entre os diferentes órgãos de estado capazes de realizar a redistribuição (item "g"). O direito, finalmente, é fundamental para definir o grau de vulnerabilidade de diferentes regras redistributivas ao problema da fuga da jurisdição (item "h").

\section{REFERÊNCIAS}

AVRAHAM, Ronen; FORTUS; David; LOGUE, Kyle. Revisiting the roles of legal rules and tax rules in income distribution: a response to Kaplow and Shavell. Iowa Law Review, Iowa City, v. 89, n. 4, p. 1125-1158, Apr. 2004.

BLUMKIN, Tomer; MARGALIOTH, Yoram. On the limits of redistributive taxation: establishing a case for equity-informed legal rules. Virgina Tax Review, v. 25, n. 1, p. 1-29, June, 2005.

DAGAN, Tsilly. Pay as you wish: the global market for tax \& legal rules. Disponível em: <http://ssrn.com/ abstract $=2506051>$. Acesso em: 25 maio 2014.

DE GEEST, Gerrit. Removing rents: why the legal system is superior to the income tax at reducing income inequality. Disponível em: <http://ssrn.com/abstract=2337720>. Acesso em: 25 maio 2014. doi: 10.2139/ ssrn.2337720. 
GALLE, Brian. Is local consumer protection law a better redistributive mechanism than the tax system? New York University Annual Survey of American Law, New York, v. 65, p. 525-544, june 2009.

GEORGAKOPOULOS, Nicholas L. Exploring the Shavellian boundary: violations from judgment-proofing, minority rights, and signalling. Disponível em: <http://ssrn.com/abstract=932908>. Acesso em: 25 maio 2014. doi: $10.2139 /$ ssrn. 932908 .

JOLLS, Christine. Behavioral economic analysis of redistributive legal rules. Vanderbilt Law Review, Tennessee, v. 51, n. 6, p. 1.653-1.677, Nov. 1998.

KLAPOW, Louis; SHAVELL, Steven. Why the legal system is less efficient than the income tax in redistributing income. Journal of Legal Studies, Chicago, v. 23, n. 2, p. 667-681, June, 1994. doi: 10.1086/467941.

KAPLOW, Louis; SHAVELL, Steven. Should legal rules favor the poor?: clarifying the role of legal rules and the income tax in redistributing income. Journal of Legal Studies, Chicago, v. 29, n. 3, p. 821-835, June, 2000 .

KEREN-PAZ, Tsachi. Torts, egalitarianism and distributive justice. Hampshire: Ashgate, 2007.

LEWINSOHN-ZAMIR, Daphna. In defense of redistribution through private law. Minnesota Law Review, Minneapolis, v. 91, n. 2, p. 326-397, 2006.

LOGUE, Kyle; AVRAHAM, Ronen. Redistributing optimally: of tax rules, legal rules, and insurance. Tax Law Review, New York, v. 56, n. 2, p. 157-258, Winter, 2003.

RAWLS, John. A theory of justice. 2. ed. Cambridge: Belknap Press, 1999.

SANCHIRICO, Chris William. Taxes versus legal rules as instruments for equity: a more equitable view. Journal of Legal Studies, Chicago, v. 29, n. 2, p. 797-820, June, 2000.

SANCHIRICO, Chris William. Deconstructing the new efficiency rationale. Cornell Law Review, New York, v. 86, n. 6, p. 1003-1089, Jul. 2001.

WEINRIB, Ernst J. The idea of private law. Cambridge: Harvard, 1995. 
Para publicar na revista Brasileira de Políticas Públicas, acesse o endereço eletrônico www.rbpp.uniceub.br

Observe as normas de publicação, para facilitar e agilizar o trabalho de edição. 